\title{
Psychiatry and the human sciences
}

\author{
MARK. A. TURNER
}

'Whenever the object studied is Man and not man as a species of animal, we find that psychopathology comes to be not only a kind of biology but also one of the Humanities.'

Karl Jaspers, 1913 (trans. 1997: p. 36)

In an important editorial in the British Journal of Psychiatry, Kendell suggested that the practice of dichotomising illness into mental and physical categories is 'archaic and deeply misleading' and 'incompatible with contemporary understanding of disease' (Kendell, 2001: p. 492). Kendell argued that since the various taxonomies of mental disorder are essentially a list of conditions treated by psychiatrists, it is a matter of pragmatism whether (for example) Alzheimer's disease is classified as mental illness and treated by a psychiatrist, or as a physical illness and treated by a neurologist. In sanctioning this approach Kendell was reiterating the claims made by Carl Gustav Hempel, who after articulating his celebrated deductive-nomological model of scientific explanation (Hempel \& Oppenheim, 1948) went on to crucially influence the development of the Diagnostic and Statistical Manual (DSM) classifications of mental illness in his 1959 landmark paper, 'Fundamentals of taxonomy' (see Hempel, 1965).

In a related and equally important article, also in the British Journal of Psychiatry, Cheng furthered the cause of scientific psychiatry by expressing the opinion that 'cultural variation in mental health is mainly in the presenting features rather than in the nature and frequency of the underlying [my italics] neuropsychiatric impairments and disorders' (Cheng, 2001: p.3). He suggested that an approach that recognised the pathoplastic effects of culture on illness behaviour and the existence of culture-general psychopathology, while at the same time respecting the biological basis of mental illness, was feasible providing that 'standardised diagnostic interview[s]... incorporated psycholinguistic equivalents from different cultures' (Cheng,
2001: p. 3). In articulating these opinions Cheng was echoing the intention of the architects of the International Classification of Diseases (ICD) and DSM classifications to create a transcultural scientific psychiatry.

Kendell and Cheng are not saying exactly the same thing, but both are promoting a scientific psychiatry, the details of which go almost unquestioned within the profession. It is, however, possible to cast doubt on the validity of their views by considering an alternative approach to the mental which is much discussed in the philosophy of mind, language and anthropology, and with which most psychiatrists are unfamiliar. The approach in question can explain two things: first, why the distinction between mental and physical illness is a necessary and unavoidable one, and second, why the claim that mental illness is the same in all cultures is an implicit assumption, rather than an empirical finding, in Cheng's cross-cultural psychiatry.

\section{MENTAL SCIENCE}

The alternative to the views of Kendell and Cheng can be seen as a distillation of ideas that have their origins in predominantly German hermeneutical works such as Johann Gustav Droysen's Grundrisse der Historik (1858), Wilhelm Dilthey's Einleitung in die Geisteswissenschaften (1883) and, more recently, Hans-Georg Gadamer's Wabrheit und Methode (1960). The central tenets of this tradition are, however, most clearly articulated in the writings of the American philosopher Donald Davidson who, partly in response to the perceived inadequacies of Hempel's account, argued that the mental is 'anomalous' and not subject to scientific laws, and that as such it can best be understood by reflecting on the nature of interpretation. Since Davidson's thinking has assimilated and progressed beyond the Hempelian neopositivism that informs current scientific psychiatry, his arguments for 'anomalism' and 'interpretationism' are likely to provide the basis for thinking that the claims of Kendell and Cheng are mistaken.

With this in mind, in his essay 'Mental events' Davidson (1970) articulates the view that there is a categorical difference between the mental and the physical and that there cannot, in any useful sense, be a science of the mental because of the impossibility of either strict psychological or strict psychophysical laws. Against psychophysical laws, Davidson argues that mental and physical concepts have different conditions of application or 'constitutive principles' and that 'there cannot be tight connections [psychophysical bridge laws] between the realms if each is to retain allegiance to its proper source of evidence' (Davidson, 1970: p. 222). On the nature of the mental, McLaughlin writes:

'Constitutive principles expressing norms of
rationality express normative truths: they say
what [mental states] an individual ought rationally
to have given that the individual has others; and
they say what an individual ought rationally to
do given the individual's [mental states]'
(McLaughlin, 1985: p. 356).

Physical theory, on the other hand, 'promises to provide a comprehensive closed system guaranteed to yield a standardised, unique description of every physical event couched in a vocabulary amenable to law' (Davidson, 1970: pp. 223-224). In the light of these different commitments the existence of psychophysical laws must a priori be impossible. If they did exist, such laws would have the intolerable effect of transmitting the conditions of application between the mental and the physical, with the result that either irrational thought and behaviour would violate the laws of physics or the mental would be constrained by physical constitutive principles in a way that would breach the norms of rationality. Davidson concluded that 'the nomological irreducibility of the psychological means ...that the social sciences cannot be expected to develop in ways exactly parallel to the physical sciences' (Davidson, 1973a: p. 230).

The argument against psychological laws derives from the view that in the natural sciences the predictive and explanatory power of laws can be improved by more accurately specifying the causal variables. In psychology, on the other hand, there is no hope of improvement in our everyday way of understanding individuals, because, 
given that psychophysical laws do not exist, there is no independent way of identifying and measuring the mental states of those individuals. Take the putative psychological law 'if a man wants to eat an acorn, then he will if the opportunity exists and no other desire overrides' (Davidson, 1973a). The difficulty with this law is that (as Evnine puts it),

'whether or not he does eat an acorn is an important factor in whether or not we interpret [my italics] him as wanting to eat one. It is not that his eating or failing to eat an acorn omelette is conclusive in determining whether or not he wants to eat one. It is just that the two parts of the putative law, the antecedent desire and the consequent action, both feature in the interpretation of an agent and hence are related to each other as parts of a holistic web' (Evnine, 1991: pp. 2l-22).

\section{PHILOSOPHICAL ANTHROPOLOGY}

The remarks quoted above indicate that a science relying on mental states is implausible. The mention of 'interpretation', however, gives an indication of the likely basis of an alternative account. The nature of interpretation can be informed by a consideration of the theoretical difficulties encountered in trying to understand the language and behaviour of individuals from other cultures. In its philosophical form this project amounts to the search for a theory of meaning for a foreign language $(L)$ which will consist of axioms and theorems that together give the semantic properties, the truth-conditions, of the sentences of the language concerned. Each theorem will consist of an English sentence that is true if and only if the foreign language sentence is true: for example, 'il fait chaud' is true in language $L$ (in this case French) if and only if it is warm. If a speaker of $L$ does assent to the sentence 'il fait chaud' only when it is warm, then one has confirmed the theorem, interpreted the foreign language sentence, and therefore made a start in constructing a theory of meaning for that language. In theory this process is repeated until eventually one comes to understand the whole of the language in question.

In pursuing the theoretical complexities of constructing such a theory, Davidson realised that if the speaker of $L$ assented to the sentence 'il fait chaud' then this was not just because 'il fait chaud' means 'it is warm', but also because the speaker believed it to be warm. Unfortunately, however - and this is the crucial point - if the speaker of $L$ believes it to be warm when it is not warm, because the evidence for the truth of the theorem is purely in the form of what sentences are assented to under which conditions then an interpreter will not know what the speaker means, since the former does not know what the latter believes. Davidson writes:

'A speaker who holds a sentence to be true on an
occasion does so in part because of what he
means, or would mean, by an utterance of that
sentence, and in part because of what he
believes. If all we have to go on is the fact of
honest utterance, we cannot infer the belief
without knowing the meaning, and have no
chance of inferring the meaning without the
belief' (Davidson, 1974: p. 142). Ideally, an interpreter needs to be able to hold an individual's beliefs constant in order to establish the meaning of that individual's words; the difficulty is, however, that beliefs require interpretation as much as do meanings. In order to resolve this difficulty, Davidson embraced the hermeneutical idea that beliefs and meanings are internally related, and introduced the 'principle of charity'. This principle asserts that when one is interpreting someone from another culture one should assume, without otherwise being able to access an internal circle, that they are psychologically similar to and, therefore, believe the same as oneself. Davidson writes that this assumption

\begin{abstract}
'is intended to solve the problem of the interdependence of belief and meaning by holding belief constant as far as possible while solving for meaning. This is accomplished by assigning truth conditions to alien sentences that make native speakers right when plausibly possible, according, of course, to our own view of what is right' (Davidson, 1973b: p. 137).
\end{abstract}

The principle of charity is a way of giving substance to the idea that people from different cultures are psychologically similar, and it enables Davidson to resist cultural relativism, albeit by an a priori rather than an empirically based argument.

\section{MENTAL AND PHYSICAL ILLNESS}

Informed by the view that a scientific approach to mental states is untenable, Kendell's arguments in favour of identifying mental and physical illness can now be assessed. In terms of aetiology, the claim that mental illness can have physical causes is not enough to sustain Kendell's claim. The physical symptoms of illness are presumably related to underlying physical causes by laws that can be sharpened as science improves our knowledge of the physical universe. In the case of mental symptoms, since there are no laws there is no such hope, and there is no reason whatsoever to think that knowledge of the phenomenology of mental illness will improve beyond its current state. This, in fact, is the main reason why-despite enormous progress in terms of the scientific understanding of physical illness in the last century-Jasper's General Psychopathology remains unsurpassed.

The different constitutive principles of the mental and physical give reason to think that not all mental illness has a physical cause. Physical symptom-concepts have physical conditions of application, whereas mental symptom-concepts, particularly those of minor mental illness and personality disorder, have broadly rational conditions of application; they relate to individuals' other beliefs, desires and actions in a normative way that cannot be captured by a theory that is formulated in a physical vocabulary. For example, the application of the concept of 'misattribution', which is likely to prove aetiologically important in somatisation disorder (Butler et al, 2001), requires a prior familiarity with the normative constraints of belief formation. However, as Margolis reminds us,

\footnotetext{
at the present time, nearly the whole of late 20th century philosophy is quite unable to provide any principled criteria of reality testing which are not obviously theoretically, historically, ideologically, culturally and locally skewed. ... Hence if schizophrenia [and one might add mental illness generally] (but not dementia of the Alzheimer's type) implicates norms of knowledge, then the theory of schizophrenia [and other mental illnesses] will involve factors that ... can[not], in principle, be assigned a somatic aetiology' (Margolis, 1994: pp. 124-125).
}

The absence of a principled relation between mental symptoms and underlying physical causes coupled with the normative nature of the mental means that the diagnosis of mental illness will, even if it is secondary to an identifiable physical cause or illness, always have to be based on an assessment of the phenomenology. There are, of course, mental illnesses that result from physical causes at a level with sufficiently general effects as to be amenable to physical intervention. Neurologists can, in principle, compete with psychiatry over the management of these disorders in a way Kendell presumably envisages - but only after mental state examinations have 
provided them with diagnoses. Furthermore, even if it did turn out that all people with a given mental illness such as depression had a given neurophysiological state in common, one could not sanction giving them a physical treatment without deferring to a mental state examination.

\section{INTERPRETATION AND CULTURE}

Cheng's views inherit the difficulties just mentioned since, in the absence of an identifiable physical basis, the culturespecificity or otherwise of mental illness becomes that of legitimately identifying cross-cultural psycholinguistic equivalents. The discussion of interpretation implied, however, that to find such equivalents an interpreter interested in mental illness is required to assume precisely what Cheng sets out to prove, namely that mental illness is the same in all cultures. In other words, without making the assumption that 'underneath' linguistic and conceptual differences different cultures really are talking about the same thing, how can one ever be sure that one's interpretations are accurate? The matter is, incidentally, complicated significantly by the decision to allow the existence of 'culture-specific illness behaviour' (Cheng, 2001: p. 1).

In resting on the assumption of something like the principle of charity, the viability of cross-cultural psychiatry, like anthropology in general, comes at a high price. Although the principle ostensibly enables cultural relativism to be avoided, it achieves this at the cost of converting what Cheng would construe as primarily empirical into an interpretative enterprise. The principle of charity, which is essentially an injunction to assume that other individuals are psychologically the same as oneself, can hardly function as a fundamental scientific principle on which to erect a science of cross-cultural psychiatry. Furthermore, if these views are right, the enormous amount of time and effort

MARK A. TURNER, MRCPsych, Duchess of Kent's Psychiatric Hospital, Catterick Garrison, North Yorkshire DL9 4DF, UK. Tel: 01748 873608; fax: 01748 873614; e-mail: markturn@dsca.mod.uk

(First received 29 April 2002, final revision 5 August 2002, accepted 29 August 2002)

that goes into 'finding' psycholinguistic equivalents should be interpreted, not as evidence of empirical rigor, but rather (as Husserl might say) as reflective of the infinite nature of the task. This is in some ways reassuring, because it carries the implication that the work of psychiatry - unlike that of physical medicine, or indeed science in general - will never be complete.

Having conceded that the project is interpretational, it might be advisable to go the whole way and admit that the distinction between mental illness and the associated illness behaviour is at best vague, and following Margolis, embrace some form of cultural relativism. It is likely, however, that over the coming years crosscultural psychiatrists will become increasingly reluctant to concede this issue, as they are better able to identify psycholinguistic equivalents. However, if other cultures continue to be exposed to Western ideas at the current rate, then the requirement for the principle of charity will gradually recede as cultures come to resemble each other. If this occurs - and one may reasonably assume that it will - then it will not indicate that cross-cultural psychiatry has come of age, but rather support the implicit claim of this editorial, that psychiatry has more in common with politics than with medicine.

\section{DECLARATION OF INTEREST}

None.

\section{REFERENCES}

Butler, A., Chalder, T. \& Wessely, S. (200I) Causal attributions for somatic sensations in patients with chronic fatigue syndrome and their partners. Psychological Medicine, 31, 97-105.
Cheng, A.T. A. (200I) Case definition and culture: are people all the same? British Journal of Psychiatry, 179, I-3.

Davidson, D. (1970) Mental events. Reprinted (1980) in Essays on Actions and Events (D. Davidson), pp. 207-227. Oxford: Clarendon Press.

_ (1973a) Psychology as philosophy. Reprinted (1980) in Essays on Actions and Events (D. Davidson), pp. 229 244. Oxford: Clarendon Press.

_ (1973b) Radical interpretation. Reprinted (1984) in Inquiries into Truth and Interpretation (D. Davidson) pp. 125-139. Oxford: Clarendon Press.

_ (1974) Belief and the basis of meaning. Reprinted (1984) in Inquiries into Truth and Interpretation (D. Davidson), pp. 15I-154. Oxford: Clarendon Press.

Dilthey, W. (1883) Einleitung in die Geisteswissenschaften. Reprinted (1989) as Introduction to the Human Sciences (eds R. Makkreel \& R. Frithjof). Princeton, NJ: Princeton.

Droysen, J. G. (1858) Grundrisse der Historik. Reprinted (1897) as Outline of the Principles of History (trans. E. B. Andrews). Boston, MA: Ginn \& Co.

Evnine, S. (1991) Donald Davidson. Oxford: Polity Press.

Gadamer, H.-G. (1960) Wahrheit und Methode Reprinted (1989) as Truth and Method (trans. J. Weinsheimer \& D. G. Marshall). New York: Crossroad.

Hempel, C. G. (1965) Fundamentals of taxonomy. In Aspects of Scientific Explanation and Other Essays in the Philosophy of Science (ed. C. G. Hempel), pp. 137-154. Glencoe, IL: Free Press.

_ \& Oppenheim, P. (1948) Studies in the logic of explanation. Philosophy of Science, 15, 135-175.

Jaspers, K. (1913) Allgemeine Psychopathologie. Reprinted (1997) as General Psychopathology (trans. J. Hoenig \& M.W. Hamilton). Baltimore, MD: Johns Hopkins University Press.

Kendell, R. E. (200I) The distinction between menta and physical illness. British Journal of Psychiatry, 178, 490-493.

Margolis, J. (1994) Taxonomic puzzles. In Philosophical Perspectives on Psychiatric Diagnostic Classification (eds M. D. Sadler \& O. P. Schwartz), pp. 104-128. Baltimore, MD. Johns Hopkins University Press.

McLaughlin, B. (1985) Anomalous monism and the irreducibility of the mental. In Actions and Events: Perspectives on the Philosophy of Donald Davidson (eds B. McLaughlin \& E. Lepore), pp. 33I-368. Oxford: Blackwell. 